\title{
Penumbuhan Budi Pekerti Berbasis Kearifan Lokal Melalui Pembelajaran Sastra Anak Pada Siswa Kelas Tinggi di Sekolah Dasar Yogyakarta
}

\author{
Anang Sudigdo \\ PGSD, FKIP, Universitas Sarjanawiyata Tamansiswa Yogyakarta \\ Jalan Batikan, Tuntungan UH-III/ I043Yogyakarta 55 I67 \\ E-mail: anang_paket3@yahoo.com
}

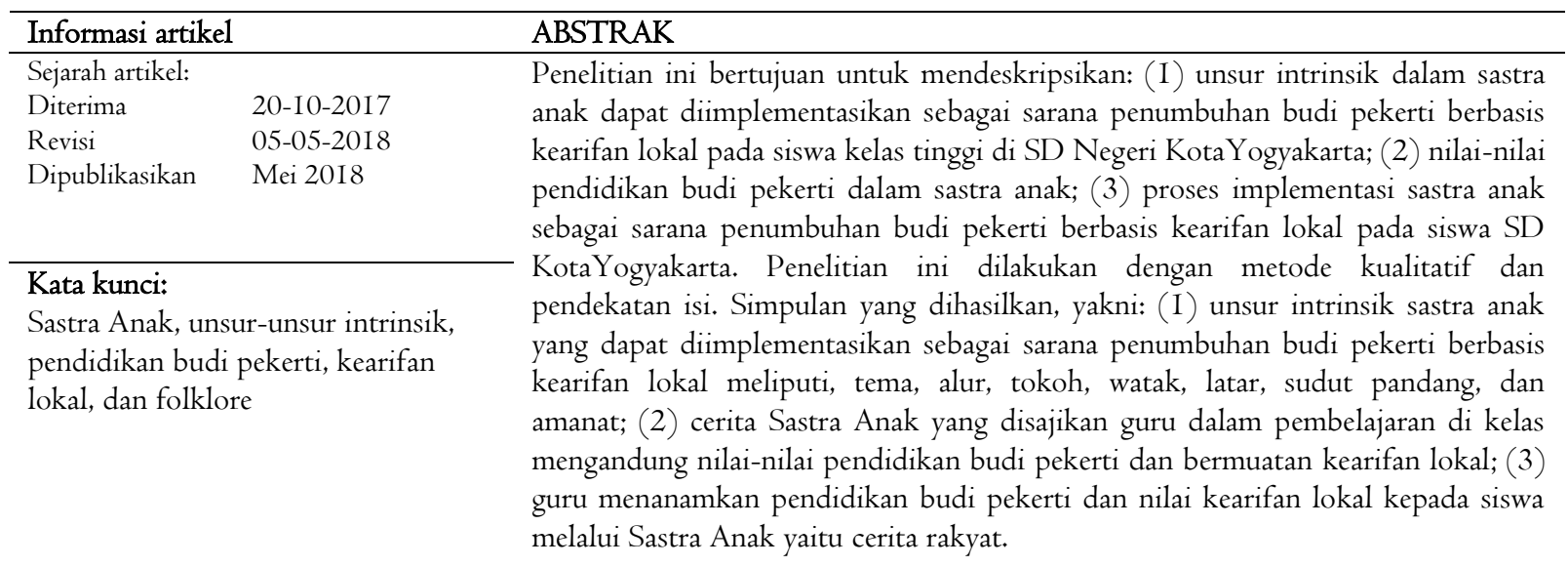

Key word:

Children's Literature, intrinsic elements, character education, local wisdom, and folklore

\begin{abstract}
This research aims to describe: (I) intrinsic element in child literature can be implemented as a way of indigenous wisdom based on local wisdom upper class students at Yogyakarta state elementary school; (2) the values of character education in children's literature; (3) the process of child literature implementation as a way of character growth based on local wisdom in elementary school students in Yogyakarta. This research is done by qualitative method and content approach. The resulting conclusions are: (I) the children's literary intrinsic element which can be implemented as a way of character development based on local wisdom including theme, plot, figures, character, setting, point of view and moral value; (2) the story Children's Literature presented by the teacher in the classroom learning contains the values of character education and culture based; (3) teachers inculcate character education to students through Children's Literature that is folklore.
\end{abstract}

Copyright (C) 2018 Universitas Ahmad Dahlan. All Right Reserved

\section{Pendahuluan}

Sastra anak merupakan suatu karya sastra terbaik sebagai bahan bacaan anak dengan karakteristik berbagai ragam, tema, dan format. Karya sastra anak dibuat untuk disajikan pada anakanak mulai dari usia dini, seperti buku berbentuk mainan, buku-buku untuk anak bayi, buku memperkenalkan alfabet, buku mengenal angka dan hitungan, buku mengenai konsep dan berbagai buku lain yang membicarakan pengalaman anak seusia itu, anak-anak lebih menyukai buku bacaan yang terdapat gambarnya sebagai ilustrasi cerita (Sarumpaet, 20I0, hlm. 2).
Hasanuddin (2015, hlm. 2) sastra anak, secara dikotomi dapat dikatakan sebagai karya sastra yang "layak" dibaca, didengar, atau dikonsumsi oleh kanak-kanak. Perkataan "layak" memberikan gambaran bahwa ada persyaratan khusus tentang boleh tidaknya, baik tidaknya, atau sesuai tidaknya teks sastra tersebut dibaca atau diperuntukan bagi kanak-kanak. Isi sastra anak adalah cerita atau pesan yang dianggab sesuai dengan tingkat emosional dan intelektualitas anak.

Pengajaran sastra anak memiliki peranan penting dalam upaya membentuk generasi yang unggul, bermoral, dan berbudi pekerti seperti yang diharapkan. Untuk mewujudkan hal tersebut peran 
pendidikan di lingkungan sekolah dan keluarga sangat diperlukan. Sastra anak perlu dikenalkan pada anak sejak anak usia dini karena sastra anak memberikan nilai hiburan pada anak dan syarat dengan nilai budi pekerti.

Salah satu alternatif pembelajaran untuk menumbuhkan budi pekerti adalah melalui sastra anak. Pembelajaran sastra anak yang terinclude dalam pelajaran Bahasa Indonesia diyakini dapat membantu proses pembentukan budi pekerti siswa. Hal ini karena dalam karya sastra anak terkandung nilai-nilai positif, yaitu nilai-nilai budaya, sosial, moral, kemanusiaan dan agama yang disampaikan melalui unsur-unsur instrinsik dan ekstrinsik. Penanaman pendidikan karakter melalui sastra anak merupakan langkah yang tepat karena sastra anak sangat dekat dengan dunia anak dan menyenangkan bagi anak. Hal tesebut senada dengan pendapat, Darwish (2015, hlm. 78) "Literature provides delight and enjoyment". berdasarkan pendapat para ahli tersebut, dapat diketahui bahwa sastra anak adalah karya sastra yang sengaja ditujukan kepada anak, ditulis oleh orang yang mampu memahami karakteristik dunia anak dan usia anak yaitu sesuai dengan tingkat emosional dan intelektual anak serta menghindari unsur pantangan bagi anak. Sastra anak mengandung pesan moral yang baik bagi anak.

Berdasarkan hasil observasi awal di lapangan menunjukkan bahwa pengajaran sastra anak yang dilakukan guru dalam menumbuhkan budi perkerti melalui sastra anak adalah menggunakan cerita anak. Guru membacakan cerita anak kepada siswa kemudian siswa menyimak cerita. Guru bersama siswa membahas unsur-unsur intrinsik yang terdapat dalam cerita. Unsur-unsur intrinsik meliputi tema, tokoh, watak, sudut pandang, alur, latar cerita, dan amanat atau pesan cerita. Guru dan siswa juga menganalisis nilai-nilai pendidikan budi pekerti yang terkandung dalam cerita.

Salah satu manfaat sastra anak anak adalah memberikan nilai pendidikan pada anak. nilai pendidikan tersebut yaitu nilai budi pekerti yang sangat baik untuk diberikan kepada anak. Pendidikan budi pekerti mengajarkan kepada anak untuk tumbuh menjadi anak yang bermoral dan berakhlak mulia sehingga anak menjadi paham (ranah kognitif), mampu merasakan (ranah efektif), dan mau melakukan (ranah psikomotor).

Sastra anak memberikan fungsi hiburan dan kesenangan serta kepuasan pada anak ketika anak membaca dan menghayati sastra anak (Winarni, 20I4, hlm. 5). Melalui sastra anak, siswa juga dapat menguatkan kemampuan membaca dan kemampuan mengapresiasi karya sastra khususnya sastra anak. Siswa merasa senang membaca karya sastra, senang mendengarkan cerita yang dibacakan guru, dan siswa mampu menerapkan dalam kehidupan sehari-hari melalui pesan moral dari cerita yang dibaca atau didengarnya. Dengan demikian, kepribadian dan kecerdasan emosional anak akan terbentuk.

Usia anak adalah usia yang masih bersifat meniru dan memerlukan bimbingan dari orang dewasa. Maka dalam hal bacaan, guru harus mampu memilihkan bacaan yang tepat untuk anak yang sesuai jiwa dan karakter anak dan sekaligus mengandung nilai karakter yang baik bagi anak. Hal tesebut senada dengan pendapat, Morgan (2012, hlm. 4) "Teacher learn how to help student to better understand the books they are reading and can use their creativity to create new stories."

Anak sudah mengenal sastra sejak kecil yaitu melalui sastra lisan. Seorang ibu menyanyikan saat anak menangis dan mendongengkan anaknya saat menjelang tidur. Sastra anak sangat syarat dengan nilai pendidikan budi pekerti. Oleh karena itu, sastra anak merupakan sarana yang tepat untuk menanamkan nilai pendidikan budi pekerti yang berbasis kearifan lokal. Penanaman pendidikan budi pekerti harus dilakukan pada anak sejak dini. Karena masa anak-anak adalah saat pembentukan jati diri seseorang yang dapat menentukan masa depan anak.

Perkembangan sastra lisan sudah banyak yang dibukukan sebagai bahan referensi bacaan untuk anak, misalnya dongeng atau cerita rakyat yang berwawasan kearifan lokal. Pengenalan sastra anak yang berbasis kearifan lokal bertujuan untuk melestarikan budaya dan nilai-nilai luhur yang berlaku pada daerah setempat.

Pada era globalisasi saat ini yang arusnya semakin deras mengkhawatirkan budaya lokal akan semakin terkikis. Budaya asing yang masuk ke Indonesia mulai mengikiskas budaya lokal yang sarat nilai warisan luhur bangsa. Kearifan lokal perlu dilestarikan dan diperkenalkan pada anak agar tidak terkikis oleh budaya luar. Melihat kenyataan saat ini, sebagian anak-anak lebih merasa senang apabila mengenal kebudyaan luar. Hal tersebut dapat menjadikan waspada terhadap keberadaan budaya lokal. Kebudayaan lokal merupakan warisan budaya dari nenek moyang yang perlu dilestarikan. Zulkarnain dan Febriamansyah (2008, hlm. 72) menjelaskan bahwa kearifan lokal berupa prinsipprinsip dan cara-cara tertentu yang dianut, dipahami, dan diaplikasikan oleh masyarakat setempat dalam berinteraksi dengan masyarakat di lingkungan sekitar dan ditransformasikan dalam bentuk sistem nilai dan norma adat. Lebih lanjut, (Raharyono, 2009, hlm. 7) menjelaskan kearifan lokal sebagai kecerdasan yang dimiliki oleh etnis tertentu yang diperoleh melalui pengalaman etnis tersebut bergulat dengan 
lingkungan hidupnya. Budaya lokal atau kearifan lokal di antaranya adalah cerita rakyat, nyanyian rakyat atau lagu daerah, adat-istiadat, makanan tradisional, tarian daerah, dan lain sebagainya yang bersifat kedaerahan. Masing-masing daerah memiliki keunggulan dan kearifan lokal yang perlu dikenalkan kepada anak-anak. salah satunya dapat dikenalkan melalui sastra anak.

Cerita rakyat yang digunakan dalam penelitian ini adalah video kartun anak "Legenda Gunung Merapi” cerita yang bermuatan lokal budaya Yogyakarta. Cerita rakyat selanjutnya merupakan karya Dian K., yaitu berjudul "Terjadinya Selat Bali” cerita yang bermuatan kearifan lokal Bali, "Lutung Kasarung" cerita yang bermuatan kearifan lokal Jawa Barat, "Asal Usul Nama Irian” cerita yang bermuatan kearifan lokal Papua Barat, "Malin Kundang" cerita yang bermuatan kearifan lokal Sumatra Barat, dan "Kisah Bulu Tengon" cerita yang bermuatan kearifan lokal Kalimantan Utara. Penggunaan buku cerita rakyat karya Dian K., terbitan Buana Ilmu Populer karena bahasa cerita sederhana dan mudah dipahami siswa, pemilihan kertasnya bagus dan mengkilap, terdapat gambar ilustrasi penuh warna sehingga memiliki daya tarik untuk membaca dan memudahkan dalam memahami isi cerita, sarat dengan nilai moral dan kearifan lokal.

Sastra anak selain bermuatan kearifan lokal juga bermuatan nilai karakter atau pendidikan budi pekerti. Ratna (20I4, hlm I42) secara definitif asasasas budi pekerti adalah pendidikan yang mengajarkan kepada anak didiknya agar memiliki pemahaman dan dengan demikian dapat melakukannya dalam kehidupan sehari-hari mengenai tingkah laku, keselarasan antara pikiran dan perasaan sesuai dengan hati nurani masing-masing. Tujuan pendidikan budi pekerti ini menjadi lebih jelas dengan adanya Undang-undang No. 4 Tahun I950, berlaku di seluruh Indonesia melalui Undang-undang No. I2 Tahun 1954, yang berbunyi: 'membentuk manusia susila yang cakap dan warga negara yang demokratis serta bertanggung jawab terhadap kesejahteraan masyarakat dan tanah air'.

Majelis Luhur Persatuan Tamansiswa (2013, hlm. 25) menjelaskan bahwa "budi pekerti" atau disebut watak yaitu bulatnya jiwa manusia yang disebut "karakter" sebagai jiwa yang "berazas hukum kebatinan". Orang yang memiliki kecerdasan budi pekerti senantiasa memikirkan dan merasakan serta selalu memakai ukuran dan dasar-dasar yang pasti dan tetap.

Berdasarkan latar belakang masalah yang dikemukakan, maka diperlukan penelitian "Penumbuhan budi pekerti berbasis kearifan lokal melalui pembelajaran sastra anak pada siswa kelas tinggi di sekolah dasar Yogyakarta”. Penumbuhan budi pekerti pada siswa dapat dilakukan melalui unsur-unsur intrinsik yang terkandung dalam sastra anak, menganalisis nilai-nilai pendidikan budi pekerti yang terkandung dalam sastra anak, dan mengimplementasikan sastra anak sebagai sarana penumbuhan budi pekerti berbasis kearifan lokal.

\section{Metode}

Jenis penelitian ini adalah penelitian kualitatif deskriptif. Prosedur dalam menentukan subjek penelitian menggunakan purposive sampling, yakni siswa kelas tinggi SD Negeri Mendungan 2, SD Kintelan I, dan SD Jurugentong. Sumber data berasal dari kejadian, tempat, dan perilaku yang terkait dengan penelitian. Cerita rakyat yang digunakan dalam penelitian ini yaitu berjudul "Terjadinya Selat Bali", "Malin Kundang", "AsalUsul Nama Irian”, "Lutung Kasarung”, dan "Kisah Bulu Tengon". Narasumber dalam penelitian ini yakni, guru dan siswa sekolah dasar kelas 4, 5, dan 6 . Prosedur pengumpulan data melalui observasi berperan serta (participant observation), wawancara mendalam (in depth interview), dan dokumentasi. Keabsahan data menggunakan triangulasi sumber dan teknik. Teknik analisis yang digunakan dalam penelitian ini adalah teknik analisis interaktif yaitu suatu teknik analisis data kualitatif yang terdiri dari tiga alur kegiatan (reduksi data, penyajian data, dan penarikan simpulan/verifikasi) yang terjadi secara bersamaan (Miles dan Huberman, 2009: 16).

\section{Hasil dan pembahasan}

\section{Unsur Intrinsik}

Penelitian yang dilakukan menghasilkan temuan unsur-unsur intrinsik yang digunakan guru dalam pembelajaran Sastra Anak sebagai penanaman budi pekerti sebagaimana diuraikan di bawah ini.

a. Tema

Stanton (2012, hlm. 36) tema merupakan aspek cerita yang sejajar dengan makna dalam pengalaman manusia; sesuatu yang menjadikan suatu pengalaman begitu diingat. Oleh karena tema merupakan pernyataan generalisasi, akan sangat tidak tepat diterapkan untuk cerita-cerita yang mengolah emosi karakter-karakternya.

Cerita anak yang digunakan guru untuk menanamkan pendidikan budi pekerti dalam pembelajaran Bahasa Indonesia khususnya Sastra Anak memiliki tema sebagai berikut, (I) "Malin Kundang" memiliki tema kedurhakaan anak pada ibunya, (2) "Asal Usul Nama 
Irian" memiliki tema semangat berjuang untuk meraih kebahagiaan, (3) "Lutung Kasarung" memiliki tema kesabaran dan ketulusan, (4) "Terjadinya Selat Bali" memiliki tema kesalahan yang dilakukan Manik Angkeran, (5) memiliki tema kesabaran dan kebaikan akan berbuah kebahagiaan.

b. Plot atau Alur Cerita

Aminuddin (2009: 83) alur adalah rangkaian cerita yang dibentuk oleh tahapan-tahapan peristiwa sehingga menjalin suatu cerita yang dihadirkan oleh para pelaku dalam suatu cerita.

Alur cerita yang disampaikan guru adalah alur maju. Alur yang terkandung dalam cerita masih sederhana sehingga anak dapat dengan mudah memahami cerita yang disampaikan oleh guru.

c. Tokoh dan Watak

Pelaku yang mengemban peristiwa dalam cerita fiksi sehingga peristiwa itu mampu menjalin suatu cerita di sebut dengan tokoh (Aminuddin, 2009:79).

Seorang tokoh yang memiliki peranan penting dalam suatu cerita disebut sebagai tokoh utama. Sedangkan tokoh yang memiliki peranan tidak penting, kehadirannya hanya mengelengkapi dan membantu tokoh utama disebut sebagai tokoh tambahan atau tokoh pembantu (Aminuddin, 2009, hlm. 79-80).

Aminuddin (2009, hlm. 80) watak dibedakan menjadi dua yaitu protagonis dan antagonis. Watak protagonis yaitu pelaku yang memiliki watak yang baik sehingga disenangi pembaca, sedangkan watak antagonis, yakni pelaku yang tidak sesuai dengan apa yang diidam-idamkan oleh pembaca.

Cerita "Terjadinya Selat Bali" memiliki tokoh dan watak, Manik Angkeran (Tamak, Boros, Suka Foyafoya), Sidhimantra (Baik, Penyayang).

Cerita "Malin Kundang" memiliki tokoh dan watak, Malin Kundang (Baik, Pekerja Keras, Durhaka), Ibu Malin Kundang (Baik, Penyayang).

Cerita "Lutung Kasarung" memiliki tokoh dan watak Purbararang (Sombong, Pemalas, Iri Hati), Lutung Kasarung (Baik, Penolong), Purbasari (Baik, Ramah, Bijaksana, Rajin,), Prabu Tapa (Baik, Bijaksana), Indrajaya (Jahat).
Cerita "Asal Usul Irian" memiliki tokoh dan watak, Mananamakrdi (Baik, Penyayang, Semangat, Tidak Pernah Menyerah), Insoraki (Baik, Setia, Bijaksana), Konori (baik), Nelayan (baik).

Cerita "Kisah Bulu Tengon" memiliki tokoh dan watak, Ku Anyi (Baik, Penyayang, Tegas, Disiplin, Suka Berbagi), Istri (Baik, Ramah, Penyayang), Jau Iru (baik, penolong), Lamiai Suri (baik, penolong).

d. Setting atau Latar Tempat

Waluyo (20II: 23) menjelaskan setting adalah tempat kejadian cerita yang berkaitan dengan aspek fisik, aspek sosiologis, dan aspek psikis. Setting juga dapat berkaitan dengan tempat dan waktu.

Latar tempat cerita "Terjadinya Selat Bali” di Gunung Agung, Bali. Latar tempat cerita "Malin Kundang" di Pesisir Pantai daerah Minangkabau, Sumatra Barat. Latar tempat cerita "Lutung Kasarung” di Kerajaan yang terletak di Jawa Barat. Latar tempat cerita "Asal Usul Irian” di Kampung Sopen, Biak Barat. Pulau Miokbudi, Biak Timur. Irian, Papua Barat. Latar tempat cerita "Kisah Bulu Tengon" di Suku Dayak, Kalimantan Utara.

e. Gaya Bercerita

Guru memilih cerita dengan gaya bahasa sederhana karena cerita disajikan kepada siswa yang belum memiliki kosa kata banyak. Bahasa yang tersaji dalam cerita tidak bertele-tele dan tidak mempunyai konflik banyak. Kesederhanaan bahasa dapat terlihat dari siswa dapat dengan mudah menangkap isi cerita.

2. Nilai-nilai Pendidikan Budi Pekerti dalam Sastra Anak

"Malin Kundang" (Sayangilah orangtuamu. Merekalah yang membawa dan merawatmu ke dunia ini. Hormati dan patuhi nasihat mereka.)

"Terjadinya Selat Bali" (Jika ada yang menolongmu saat mengalami kesusahan, berterimakasihlah. Jangan sombong dan meminta lebih. Itu akan membuat oranglain enggan menolongmu.)

"Lutung Kasarung" (Rasa iri tidak akan membawamu maju. Jangan iri pada temanmu yang maju dan sukses. Perbaiki dirimu dan siaplah untuk maju!)

"Asal Usul Irian" (Jangan mudah menyerah meski orang sekitarmu merendahkanmu dan 
menghinamu. Teruslah bersemangat, maka masa depan cerah akan menantimu.)

"Kisah Bulu Tengon" (Orang yang baik akan mendapatkan hal-hal yang baik pula. Meski kadang ada kesulitan yang menyertai, akan selalu ada penyelesaiannya.).

3. Nilai Kearifan Lokal dalam Cerita Rakyat

a. "Malin Kundang"

Siswa dikenalkan dengan pakaian adat Minangkabau yang bernama Bundo Kanduang atau Limapeh Rumah Nan Gadang.

I. Siswa dikenalkan rumah adat Minangkabau yang bernama Rumah Gadang atau Rumah Godang.

2. Siswa menjadi tahu cerita tersebut merupakan legenda dari daerah Minagkabau, Sumatra Barat berupa batu yang berbetuk mirip dengan manusia.

b. "Terjadinya Selat Bali"

I. Siswa dikenalkan pakaian adat masyarakat Bali yang bernama Payas Madya yang terdiri dari kain panjang, alas kaki, umpal dan kampuh.

2. Siswa menjadi tahu cerita tersebut merupakan legenda dari daerah Bali, yang ceritanya masih berkaitan dengan dewa-dewa.

c. "Lutung Kasarung"

I. Siswa dikenalkan pakaian kerajaan zaman dahulu.

2. Siswa menjadi tahu cerita tersebut merupakan legenda daerah Jawa Barat.

d. "Asal Usul Irian"

I. Siswa dikenalkan pakaian tradisional dari daerah Papua Barat.

2. Siswa menjadi tahu cerita tersebut merupakan legenda terbentuknya daerah Irian.

3. Siswa menjadi tahu kehidupan masyarakat Papua yang tersebar menjadi beberapa Kampung, Pulau dan Suku.

f. "Kisah Bulu Tengon"

I. Siswa dikenalkan pakaian tradisional dari Suku Dayak, Kalimantan Utara.

2. Siswa menjadi tahu cerita tersebut merupakan cerita rakyat Suku Dayak, Kalimantan Utara dimana Ku Anyi menemukan sebuah telur dan saat telur menetas menjadi 2 anak manusia.
3. Siswa menjadi tahu kehidupan masyarakat Suku Dayak sebagai pemburu.

Orang yang baik akan mendapatkan hal-hal yang baik pula. Meski kadang ada kesulitan yang menyertai, akan selalu ada penyelesaiannya.

\section{Proses Implementasi Sastra Anak sebagai Sarana Penumbuhan Budi Pekerti pada Siswa $\mathrm{SD}$}

Guru memulai pelajaran dengan mengawali berdoa bersama, mendoakan orangtua, diri sendiri dan teman. Setelah selesai berdoa, guru mengajak siswa untuk lebih bersemangat salah satunya dengan cara mengajak siswa untuk tepuk semangat dan menyanyikan lagu "Aku Sayang Ibu”. Siswa sangat antusias dan penuh semangat melakukan tepuk semangat dan menyanyikan lagu "Aku Sayang Ibu".

Setelah selesai menyanyikan lagu. Guru menyampaikan nilai pendidikan yang terkandung dalam lagu anak tersebut yaitu harus menghormati kedua orangtua, guru, dan saudara. Selanjutnya guru memulai pelajaran yaitu Bahasa Indonesia khususnya Sastra Anak. Guru membagi siswa ke dalam kelompok secara heterogen kemudin guru menjelaskan nilai-nilai pendidikan budi pekerti dalam sastra anak melalui unsur-unsur intrinsik karya sastra. Guru memutarkan video cerita rakyat yang berjudul "Legenda Gunung Merapi” yang berasal dari Yogyakarta. Video yang digunakan guru adalah video kartun anak. Penggunaan video yang kartun anak adalah disesuaikan dengan karakteristik usia anak. Siswa secara seksama menyaksikan video "Legenda Gunung Merapi”. Guru menyampaikan pesan moral yang terkandung. Selanjutnya guru mengajak siswa untuk belajar di taman sekolah. Guru melakukan pelajaran di luar kelas agar suasana lebih menyenangkan dan siswa bisa mengamati lingkungan sekitar. Setelah berada di taman sekolah, guru mendongengkan cerita rakyat yang berjudul "Asal Usul Gubug Rubuh” cerita rakyat yang berasal dari Yogyakarta.. Siswa menyimak guru selama mendongeng. Saat guru mendongeng terjadi komunikasi dua arah antara guru dan siswa sehingga kedekatan antara guru dan siswa terjalin suasana pun menjadi lebih menyenangkan. Setelah guru selesai mendongeng, masing-masing kelompok berdiskusi untuk menganalisis unsur-unsur intrinsik yang terkandung dalam dongeng. Masing-masing kelompok juga menganalisis nilai pendidikan budi pekerti dan nilai kearifan lokal yang terkandung dalam dongeng. Setelah selesai berdiskusi, masingmasing kelompok menyampaikan hasil analisisnya. Guru bersama siswa merayakan hasil diskusi dengan 
menyanyikan yel-yel. Siswa sangat ceria dalam pembelajaran yang telah dilakukan guru.

Setelah diskusi pertama selesai, guru membagikan buku cerita anak kepada masing-masing kelompok. Buku cerita anak yang digunakan guru adalah cerita rakyat yang berwawasan kebudayaan lokal atau kearifan lokal. Cerita rakyat tersebut yaitu berjudul "Terjadinya Selat Bali", "Malin Kundang", "Asal-Usul Nama Irian", "Lutung Kasarung", dan "Kisah Bulu Tengon".

Setelah guru selesai membacakan cerita, guru meminta siswa untuk mendiskusikan unsur-unsur intrinsik dan nilai pendidikan budi pekerti serta nilai budaya lokal yang terkandung dalam cerita bersama anggota kelompoknya masing-masing. Siswa dengan tertib berdiskusi dengan kelompok masing-masing. Masing-masing siswa terlihat telah memiliki karakter dalam melakukan diskusi kelompok. Hal tersebut terlihat siswa sangat tertib dan aktif dalam berdiskusi. Setelah selesai berdiskusi, guru membahas hasil pekerjaan siswa. Guru meminta masing-masing kelompok untuk mempresentasikan hasil diskusi yang telah dilakukan. Setelah selesai presentasi, guru menyampaikan nilai-nilai budi pekerti dan nilai kearifan lokal yang terkandung dalam cerita. Guru menggunakan Sastra Anak dalam menanamkan pendidikan budi pekerti dan nilai kearifan lokal pada siswa karena siswa dapat lebih mudah menerima dan menangkap pesan moral yang terkandung dalam cerita. Buku cerita tersebut juga terdapat ilustrasi yang dapat memudahkan siswa untuk memahami isi cerita.

\section{Simpulan}

Penanaman budi pekerti dapat dilakukan melalui sastra anak pada pembalajaran Bahasa Indonesia. Dengan menggunakan sastra anak, siswa dapat dengan mudan menerima pesan moral yang terkandung dalam cerita. Sastra anak yang digunakan guru dalam menanamkan budi pekerti pada siswa adalah cerita rakyat yang bermuatan nilai kerarifan lokal. Pengajaran sastra anak yang dilakukan guru adalah di dalam kelas dan di luar kelas. Penyajian guru dalam menyampaikan cerita rakyat, guru menggunakan media film kartun anak dengan judul "Legenda Gurung Merapi”. Selain menggunakan film kartun anak, guru juga menyajikan dengan cara mendongengkan. Dongeng yang dibacakan guru yaitu "Asal Usul Gubug Rubuh". Penanaman budi pekerti juga dapat dilakukan oleh guru dengan mengajak siswa belajar di luar kelas. Guru membentu kelompok secara heterogen, guru membagikan cerita rakyat yang bermuatan kearifan lokal. Siswa mendiskusikan kandungan nilai pendidikan budi pekerti dan nilai kearifan lokal yang terkandung dalam cerita. Pembelajaran yang dilakukan guru, membuat siswa menjadi lebih mudah memahami nilai pendidikan budi pekerti dan dapat menerapkan dalam kehidupan sehari-hari. Sekaligus siswa dapat mengetahui nilai kerarifan lokal pada suatu daerah.

Berdasarkan hasil temuan penelitian ini, penulis menyarankan pada guru-guru khususnya dalam mata pelajaran Bahasa Indonesia. Guru dapat menggunakan Sastra Anak sebagai sarana penumbuhan budi pekerti sekaligus sebagai pengenalan nilai kearifan lokal pada siswa.

\section{Persantunan}

Artikel ini disusun atas dorongan dan dukungan dari berbagai pihak Ucapan terima kasih disampaikan kepada pimpinan Program Studi Pendidikan Bahasa dan Sastra Indonesia, FKIP, UST, dan teman-teman sejawat. Teristimewa Ayahanda dan Bunda yang doanya terus mengalir. Semoga artikel ini dapat memberikan kontribusi dalam pembelajaran terutama dalam kegiatan literasi kritis.

\section{Daftar Pustaka}

Aminuddin. (2009). Pengantar Apresiasi Karya Sastra. Bandung: Sinar Baru Algensindo.

Darwish, Salwa Al. (20I5). Literacy and Children's literature: Evidence from Actual Classroom Practice. Journal of Education and Training Studies. 3 (I), 78-83.

Faza. (2017). Cerita Asli Nusantara. Jakarta: PT ELEX MEDIA KOMPUTINDO

Hasanuddin WS. (20I5). Sastra Anak Kajian Tema, Amanat dan Teknik Penyampaian Cerita Anak Terbitan Surat Kabar. Bandung: Angkasa.

K, Dian. (20I7). SERI CERITA RAKYAT 34 PROVINSI: KISAH BULU TENGON. Jakarta: Bhuana Ilmu Populer Kelompok Gramedia.

K, Dian. (20I7). SERI CERITA RAKYAT 34 PROVINSI: ASAL USUL IRIAN. Jakarta: Bhuana Ilmu Populer Kelompok Gramedia.

K, Dian. (20I7). SERI CERITA RAKYAT 34 PROVINSI: LUTUNG KASARUNG. Jakarta: Bhuana Ilmu Populer Kelompok Gramedia.

K, Dian. (20I7). SERI CERITA RAKYAT 34 PROVINSI: MALIN KUNDANG. Jakarta: Bhuana Ilmu Populer Kelompok Gramedia.

K, Dian. (20I8). SERI CERITA RAKYAT 34 PROVINSI: TERJADINYA SELAT BALI. 
Jakarta: Bhuana Ilmu Populer Kelompok Gramedia.

K, Dian. (20I8). SERI CERITA RAKYAT 34 PROVINSI: TERJADINYA SELAT BALI. Jakarta: Bhuana Ilmu Populer Kelompok Gramedia.

Majelis Luhur Persatuan tamansiswa. (20I3). KI HADJAR DEANTARA Pemikiran, Konsepsi, Keteladanan, Sikap Merdeka I (Pendidikan). Yogyakarta: UST-Press.

Miles, Matthew B. dan A. Michael Huberman. (2009). Analisis Data Kualitatif. Jakarta: UI-Press.

Morgan, Bobbette M. (2012). Teaching Cooperative Learning with Children's Literature. Jurnal National Forum of Teacher Education Journal. Vol. 22, No. 3: I-I2.

Raharyo, F.X. (2009). Kearifan Budaya dalam Kata. Jakarta: Wedatama Widyasastra.

Ratna, Nyoman Kutha.(20I4). Peranan Karya Sastra, Seni, dan Budaya dalam Pendidikan Karakter. Yogyakarta: Pustaka Pelajar.

Sarumpaet, Riris. Toha. (2010). Pedoman Penelitian Sastra Anak. Jakarta: Yayasan Pustaka Obor Indonesia.

Stanton, Robert. 2012. Teori Fiksi Robert Stanton. Yogyakarta: Pustaka Belajar.

Waluyo, Herman J. (20II). Pengkajian dan Apresiasi Prosa Fiksi. Surakarta: UNS Press.

Winarni, Retno. (2014). Kajian Sastra Anak. yogyakarta: Graha Ilmu.

Zulkarnain, A. Ag. dan Febriamansyah, R. (2008). Kearifan Lokal dan Pemanfaatan dan Pelestarian Sumberdaya Pesisir. Jurnal Agribisnis Kerakyatan, I, 69-85. 